\title{
Goal-directed fluid restriction during brain surgery: a prospective randomized controlled trial
}

\author{
Jinfeng Luo, Jing Xue, Jin Liu, Bin Liu, Li Liu and Guo Chen*
}

\begin{abstract}
Background: The value of goal-directed fluid therapy in neurosurgical patients, where brain swelling is a major concern, is unknown. The aim of our study was to evaluate the effect of an intraoperative goal-directed fluid restriction (GDFR) strategy on the postoperative outcome of high-risk patients undergoing brain surgery.

Methods: High-risk patients undergoing brain surgery were randomly assigned to a usual care group (control group) or a GDFR group. In the GDFR group, (1) fluid maintenance was restricted to $3 \mathrm{ml} / \mathrm{kg} / \mathrm{h}$ of a crystalloid solution and (2) colloid boluses were allowed only in case of hypotension associated with a low cardiac index and a high stroke volume variation. The primary outcome variable was ICU length of stay, and secondary outcomes were lactates at the end of surgery, postoperative complications, hospital length of stay, mortality at day 30 , and costs.

Results: A total of 73 patients from the GDFR group were compared with 72 patients from the control group. Before surgery, the two groups were comparable. During surgery, the GDFR group received less colloid (1.9 \pm 1.1 vs. $3.9 \pm 1.6 \mathrm{ml} / \mathrm{kg} / \mathrm{h}, p=0.021)$ and less crystalloid ( $3 \pm 0 \mathrm{vs.} 5.0 \pm 2.8 \mathrm{ml} / \mathrm{kg} / \mathrm{h}, p<0.001)$ than the control group. ICU length of stay was shorter (3 days [1-5] vs. 6 days [3-11], $p=0.001$ ) and ICU costs were lower in the GDFR group. The total number of complications (46 vs. 99, $p=0.043$ ) and the proportion of patients who developed one or more complications (19.2 vs. $34.7 \%, p=0.034$ ) were smaller in the GDFR group. Hospital length of stay and costs, as well as mortality at 30 day, were not significantly reduced.
\end{abstract}

Conclusion: In high-risk patients undergoing brain surgery, intraoperative GDFR was associated with a reduction in ICU length of stay and costs, and a decrease in postoperative morbidity.

Trial registration Chinese Clinical Trial Registry ChiCTR-TRC-13003583, Registered 20 Aug, 2013

Keywords: Fluid management, Goal-directed therapy, Goal-directed fluid restriction, Brain surgery, Postoperative complications, ICU length of stay

\section{Background}

Perioperative fluid administration has been shown to be a major determinant of postoperative outcome [1]. The amount of fluid administered during the perioperative period depends on multiple factors such as preoperative hydration, intraoperative blood loss, hemodynamic stability, as well as habits and believes of anesthesiologists and

\footnotetext{
*Correspondence: grace_chenguo@hotmail.com

Department of Anesthesiology and Translational Neuroscience Center, West China Hospital, Sichuan University, No. 37 Guoxue Xiang, Wuhou District, Chengdu 610041, Sichuan, People's Republic of China Jinfeng Luo and Jing Xue are co-first authors
}

surgeons [2]. Fluid needs may be highly variable from one patient to the other and are hardly predictable from classical physiological parameters such as heart rate, blood pressure, and central venous pressure. Fluid titration based on the measurements of advanced hemodynamic parameters, such as cardiac output and dynamic predictors of fluid responsiveness, has been shown to be useful to improve the outcome of patients undergoing major abdominal, vascular, and orthopedic procedures [3-6].

Whether such strategies may also be useful in patients undergoing brain surgery is unknown. In this specific context, the temptation is to keep patients as dry as 
possible to prevent brain swelling. However, blinded or uncontrolled fluid restriction may expose patients to hypovolemia-related complications [1]. We hypothesized that advanced hemodynamic measurements may be useful to objectively balance the risks of fluid restriction (hypovolemia, hypotension, and cerebral ischemia) with the risk of inducing or worsening cerebral edema $[7,8]$. In line with this concept, we designed an intraoperative fluid management protocol where minimal fluid maintenance with a crystalloid solution (fluid restriction) was combined with the administration of fluid boluses in case of severe and documented hypovolemia.

The goal of the present study was therefore to assess the effects of an intraoperative goal-directed fluid restriction (GDFR) strategy on the postoperative outcome of high-risk patients undergoing brain surgery.

\section{Methods}

\section{Patient selection}

Adult patients undergoing elective craniotomy for brain tumor resection, brain abscess, or intracranial aneurysm were considered for enrollment. Inclusion criteria were age $>18$, ASA score III or IV, and expected duration of surgery $>2 \mathrm{~h}$. Patients with a body weight $<40 \mathrm{~kg}$ or $>100 \mathrm{~kg}$ were excluded, as well as patients with cardiac arrhythmia (well-known limitation to the use of the stroke volume variation as an indicator of fluid responsiveness) [9]. The study was approved by the Ethical Committee of the West China Hospital from Sichuan University (No. 2012-104). After obtaining written informed consent, patients were randomly assigned to a standard fluid management group (Control) or to a GDFR group. A random number table was used to generate the random number sequence. All random numbers were concealed in sealed envelopes and assigned to a patient when entering the operating room.

\section{Intraoperative monitoring and management}

In addition to pulse oximetry, capnography, and heart rate monitoring, all patients had a radial arterial line in place for continuous blood pressure monitoring and a BIS sensor in place to monitor depth of anesthesia. Tidal volume was set at $8 \mathrm{ml} / \mathrm{kg}$ and respiratory frequency was adapted to maintain end-tidal $\mathrm{CO}_{2}$ between 30 and $35 \mathrm{mmHg}$. Anesthesia induction was done with propofol $(2 \mathrm{mg} / \mathrm{kg})$ and rocuronium $(1 \mathrm{mg} / \mathrm{kg})$, and then propofol and remifentanil were used to maintain depth of anesthesia (BIS in the range 40-60). Body temperature was maintained close to normal using warmed solutions and insulation blankets. Per our neurosurgical policy, all patients received mannitol the day before surgery $(250 \mathrm{ml})$, at the beginning of the surgical procedure $(250 \mathrm{ml})$, and the day after surgery $(125 \mathrm{ml})$.
In the control group, no recommendation was given for fluid and hemodynamic management during and after surgery, and therapeutic decisions were left at the discretion of the attending anesthesiologist and intensivist. In the GDFR group and during surgery, fluid maintenance was set at $3 \mathrm{ml} / \mathrm{kg} / \mathrm{h}$ of normal saline with an infusion pump, and additional colloid (gelatins or hydroxyethyl starches) boluses $(200 \mathrm{ml})$ were allowed only in case of systemic hypotension (MAP $<65 \mathrm{mmHg}$ ) with a cardiac index $(\mathrm{CI})<2.5 \mathrm{l} / \mathrm{min} / \mathrm{m}^{2}$ and a stroke volume variation $(\mathrm{SVV})>15 \%$. In case of hypotension with a $\mathrm{CI}>2.5$, the recommendation was to give a vasopressor. If $\mathrm{CI}$ was $<2.5$ and SVV $<15 \%$, the recommendation was to give an inotrope. The FloTrac/Vigileo system (Edwards Lifesciences, Irvine, $\mathrm{CA}$ ) was used to continuously monitor $\mathrm{CI}$ and SVV.

\section{Outcome variables}

The primary outcome variable was ICU length of stay. Secondary outcome variables were lactates at the end of surgery, postoperative complications at day 30, postoperative morbidity (the proportion of patients who developed one or more complications) at day 30 , mortality at day 30 , hospital length of stay, and costs.

\section{Statistical analysis}

Median ICU length of stay was $5 \pm 1.6$ days in our institution, and we assumed that GDFR may decrease it by 1 day or $20 \%$. A study sample size of 60 patients in each group was calculated for two-sided tests with type I error of $5 \%$ and power of $90 \%$. Owing to an anticipated loss of several patients entering the study, we planned to include 75 patients in each group. For a test of normal distribution, the Kolmogorov-Smirnov test was used. Continuous data with normal distribution were tested with paired or unpaired $t$ tests, non-normally distributed data using Mann-Whitney $U$ test and Wilcoxon rank-sum test for unpaired and paired results, respectively. Changes in lactate over time were tested using analysis of variance (ANOVA) on repeated measurements. Categorical data were tested using Chi-square test and Chi-square test for trend. Data are presented as mean \pm standard deviation when normally distributed and as median [interquartile ranges] in case of abnormal distribution. A $p<0.05$ was considered statistically significant for all tests. All calculations were done with $\mathrm{MedCalc}^{\circledR}$ version 10.4.8.0 (MedCalc Software, Mariakerke, Belgium).

\section{Results}

A total of 150 patients were randomized (75 in each group). Despite preoperative approval, five patients refused to participate in the study after surgery and had to be excluded from the analysis. Thus, 73 patients from 
the GDFR group were compared to 72 patients from the control group.

\section{Baseline and surgical characteristics}

Reasons for surgery were brain tumor $(\mathrm{n}=87)$, intracranial aneurysm $(\mathrm{n}=55)$, or brain abscess $(\mathrm{n}=3)$ and were well balanced between the two groups (Table 1). The GDFR group and the control group were comparable in terms of age, comorbidities, ASA score, and POSSUM score (Table 1). Surgery duration was comparable in both groups as well as intraoperative estimated blood loss (Table 2). During surgery, the GDFR group received significantly less colloid and crystalloid than the control group (Table 2).

\section{Outcome variables}

The ICU length of stay was significantly shorter in the GDFR group ( 3 days [1-5] vs. 6 days [3-11], $p=0.001$ ) (Fig. 1). At the end of the surgical procedure, lactates were lower in the GDFR group $(1.79 \pm 0.85$ vs. $2.23 \pm 1.36 \mathrm{mmol} / \mathrm{l}, p=0.003)$. The total number of

Table 1 Preoperative characteristics of the study population

\begin{tabular}{|c|c|c|c|}
\hline & $\begin{array}{l}\text { GDFR group } \\
(n=73)\end{array}$ & $\begin{array}{l}\text { Control group } \\
(n=72)\end{array}$ & $p$ value \\
\hline Male/female & $30: 43$ & $32: 40$ & 0.738 \\
\hline Age & $61 \pm 13$ & $62 \pm 13$ & 0.693 \\
\hline Age $\geq 70$ years & 20 & 24 & 0.474 \\
\hline Weight (kg) & $59 \pm 11$ & $60 \pm 12$ & 0.417 \\
\hline Height (cm) & $160 \pm 8$ & $162 \pm 7$ & 0.105 \\
\hline POSSUM (physiology score) & $21 \pm 7$ & $23 \pm 6$ & 0.151 \\
\hline POSSUM (operative score) & $13 \pm 4$ & $13 \pm 3$ & 0.394 \\
\hline ASA (3:4) & $70: 3$ & $70: 2$ & 1.000 \\
\hline \multicolumn{4}{|l|}{ Comorbidities } \\
\hline Coronary artery disease & 5 & 7 & 0.563 \\
\hline Hypertension & 45 & 37 & 0.243 \\
\hline Peripheral artery disease & 0 & 0 & 1.000 \\
\hline COPD & 11 & 18 & 0.151 \\
\hline $\begin{array}{l}\text { Other pulmonary pathol- } \\
\text { ogy }\end{array}$ & 4 & 5 & 0.745 \\
\hline Cerebrovascular disease & 26 & 29 & 0.610 \\
\hline Diabetes mellitus & 10 & 11 & 0.818 \\
\hline Chronic kidney disease & 1 & 1 & 0.992 \\
\hline Malignancy & 33 & 30 & 0.738 \\
\hline \multicolumn{4}{|l|}{ Diagnosis } \\
\hline Intracranial aneurysm & 26 & 29 & 0.610 \\
\hline Intracranial mass & 46 & 41 & 0.500 \\
\hline Brain abscess & 1 & 2 & 0.620 \\
\hline
\end{tabular}

Values are presented as mean \pm standard deviation

POSSUM physiological and operative severity score for the enumeration of mortality and morbidity, COPD chronic obstructive pulmonary disease complications and the proportion of patients who developed one or more postoperative complications were lower in the GDFR group, as well as ICU costs (Table 3). Median hospital length of stay was decreased by 2 days, but the difference did not reach statistical significance (Table 3). No differences were found in heart rate, mean arterial pressure, $\mathrm{P}_{\mathrm{ET}} \mathrm{CO}_{2}$, natremia, and urine output during the surgery between the two groups (Table 4).

\section{Discussion}

In high-risk patients undergoing brain surgery, our study shows that the use of GDFR was associated with a decrease in fluid volumes, less postoperative complications, and a shorter ICU length of stay.

Many studies have investigated the value of goaldirected fluid therapy in patients undergoing major abdominal, vascular, and orthopedic surgeries [3-6]. Conflicting results have been reported, but recent metaanalysis [3-6] has suggested an overall reduction in postoperative morbidity around $25-50 \%$, associated with a 1-2-day reduction in hospital length of stay. As far as we know, this is the first study investigating the effects of a goal-directed fluid strategy in patients undergoing brain surgery. The main objective of goal-directed strategies is to rationalize the way fluid is administered during the perioperative period [10]. A U-shaped relationship has been described between the perioperative fluid volume and postoperative complications [1]. Patients who do not receive enough fluid may develop complications related to hypovolemia, such as acute renal failure, myocardial injury, and cerebral ischemia. On the other hand, patients receiving too much fluid may develop complications associated with fluid overload, such as tissue edema, which may be responsible for prolonged mechanical ventilation and delayed wound healing [11].

For specific surgical procedures, such as pneumonectomy, liver resection, and neurosurgery, the temptation has always been to keep patients as dry as possible to prevent pulmonary edema, surgical bleeding, and brain swelling, respectively. However, blinded or uncontrolled fluid restriction may expose patients to hypovolemiarelated complications $[1,12]$. We hypothesized that advanced hemodynamic measurements may be useful to prevent both insufficient and excessive fluid management and improve postoperative outcome. We therefore designed an intraoperative fluid management protocol where minimal fluid maintenance with a crystalloid solution (fluid restriction) was combined with the administration of fluid boluses only in case of severe hypovolemia defined by the association of a low cardiac index with a high SVV. The SVV has been shown to be useful to predict fluid responsiveness in many different settings [13]. Pending limitations are respected [9]; SVV >10-13\% 
Table 2 Patient characteristics during and $24 \mathrm{~h}$ after surgery

\begin{tabular}{|c|c|c|c|}
\hline & GDFR group $(n=73)$ & Control group $(n=72)$ & $p$ value \\
\hline \multicolumn{4}{|l|}{ Patient position } \\
\hline Supine position (n) & 41 & 45 & 0.500 \\
\hline Left-lateral position (n) & 18 & 14 & 0.549 \\
\hline Right-lateral position (n) & 12 & 10 & 0.818 \\
\hline Prone position (n) & 2 & 3 & 0.679 \\
\hline \multicolumn{4}{|l|}{ Beginning of surgery } \\
\hline $\mathrm{Cl}\left(\mathrm{ml} / \mathrm{min} / \mathrm{m}^{2}\right)$ & $3 \pm 1.2$ & NA & NA \\
\hline SWV (\%) & $12 \pm 5$ & NA & NA \\
\hline \multicolumn{4}{|l|}{ During surgery } \\
\hline Crystalloids (ml/kg/h) & $3 \pm 0$ & $5.0 \pm 2.8$ & $<0.001$ \\
\hline Colloids (ml/kg/h) & $1.9 \pm 1.1$ & $3.9 \pm 1.6$ & 0.021 \\
\hline Colloids (ml) & $563 \pm 550$ & $1050 \pm 548$ & $<0.001$ \\
\hline Colloids (nb of bolus per patient) & $3 \pm 3$ & $5 \pm 3$ & $<0.001$ \\
\hline Autologous blood transfusion (ml) & $n=5,280 \pm 109$ & $\mathrm{n}=14,375 \pm 198$ & 0.224 \\
\hline Red blood cell (ml) & $n=3,400 \pm 200$ & $\mathrm{n}=2,400 \pm 282$ & 0.089 \\
\hline Fresh frozen plasma (ml) & 0 & 0 & 1 \\
\hline Estimated blood loss (ml) & $287 \pm 179$ & $305 \pm 273$ & 0.535 \\
\hline Metaraminol (no. of patients) & 39 & 18 & $<0.001$ \\
\hline Ephedrine (no. of patients) & 40 & 21 & $<0.001$ \\
\hline Dopamine (no. of patients) & 5 & 3 & 0.479 \\
\hline Dobutamine (no. of patients) & 1 & 0 & 0.319 \\
\hline Norepinephrine (no. of patients) & 3 & 3 & 0.981 \\
\hline \multicolumn{4}{|l|}{ End of surgery } \\
\hline $\mathrm{Cl}\left(\mathrm{ml} / \mathrm{min} / \mathrm{m}^{2}\right)$ & $3.6 \pm 0.7$ & NA & NA \\
\hline SWV (\%) & $7 \pm 2$ & NA & NA \\
\hline Length of surgery (min) & $274 \pm 72$ & $276 \pm 66$ & 0.864 \\
\hline Dopamine (n) & 1 & 0 & 0.319 \\
\hline Norepinephrine (n) & 0 & 1 & 0.312 \\
\hline \multicolumn{4}{|l|}{$24 \mathrm{~h}$ after surgery } \\
\hline Crystalloids (ml/kg/h) & $2.6 \pm 1.3$ & $2.6 \pm 0.8$ & 0.881 \\
\hline Colloids (ml/kg/h) & $0.2 \pm 0.3$ & $0.2 \pm 0.3$ & 0.868 \\
\hline Blood (ml/kg/h) & 0 & 0 & 0.746 \\
\hline Fresh frozen plasma (ml) & 0 & 0 & 0.744 \\
\hline Estimated blood loss (ml) & $98 \pm 65$ & $115 \pm 99$ & 0.206 \\
\hline Norepinephrine (n) & 3 & 3 & 0.981 \\
\hline Dopamine (n) & 5 & 3 & 0.479 \\
\hline Vasodilatation therapy (n) & 5 & 11 & 0.105 \\
\hline Diuretic support (n) & 45 & 38 & 0.281 \\
\hline
\end{tabular}

Values are presented as mean \pm standard deviation

$\mathrm{Cl}$ cardiac index, HR heart rate, MAP mean arterial pressure, N/A not applicable, SVV stroke volume variation

identifies fluid responder patients with high sensitivity and specificity [13]. We decided to use a higher cutoff value to keep our patients on the "dry" side, but we also decided to allow fluid boluses when SVV was $>15 \%$ to prevent excessive fluid restriction and hypovolemiarelated complications. Goal-directed fluid strategies have the advantage to rationalize the way patients are treated [10]. However, we believe that fluid management protocols must be adapted to clinical and surgical situations. The use of high SVV target values (around 18-20\%) has recently been proposed in patients undergoing liver resection to limit surgical bleeding as much as possible [14]. We thought it might be wise to adopt a similar strategy in neurosurgical patients to minimize cerebral edema. With our GDFR protocol, patients received less crystalloid and colloid than the control group, but did not 


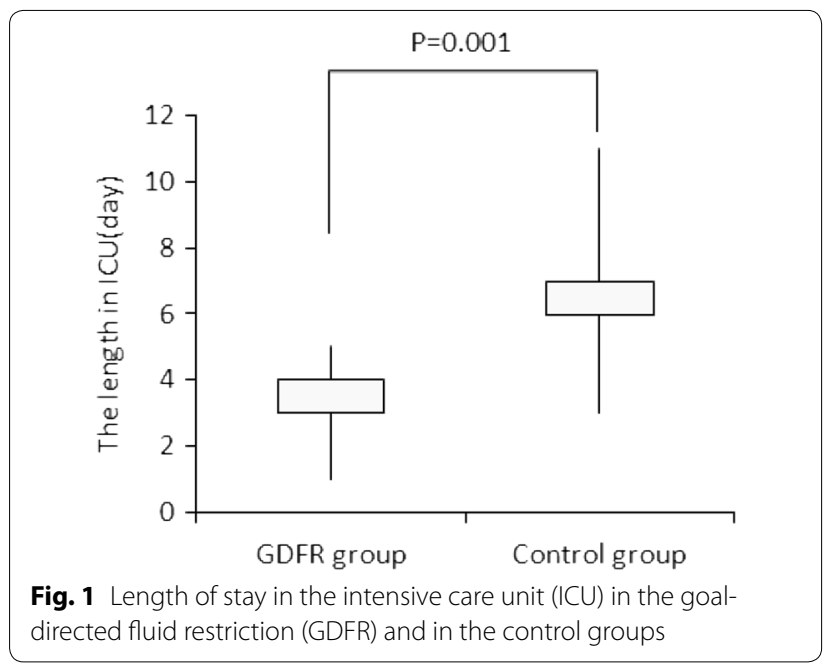

develop more often hypovolemia-related complications such as acute kidney and myocardial injury.

Our study also showed a significant reduction in ICU costs with GDFR, which is logical when considering the observed reduction in ICU length of stay, likely related to the lower number of patients who developed complications (Table 3). Sadique et al. [15] recently reported the financial results of the large UK Optimise trial and showed that patients treated with goal-directed fluid therapy were on average $£ 400$ less expensive to treat than control patients. In patients undergoing head and neck surgery in the USA, in whom ICU length of stay was significantly reduced when using goal-directed fluid therapy, Hand et al. [16] recently reported savings exceeding $\$ 3000$ per patient. Surgical and anesthesia costs in China are not comparable to those observed in the UK or in the USA. However, as suggested by previous studies $[17,18]$ our financial findings confirm that the improvement in postoperative outcome may offset the costs associated with the implementation of goal-directed fluid therapy.

Our study has several limitations. First, this is a single-center study where we compared a GDFR strategy to standard hemodynamic management at West China Hospital in Chengdu, Sichuan. We also focused on highrisk patients (ASA III \& IV). Thus, our results may not be extrapolated to other institutions having different anesthesia and surgical practices, as well as to low-risk (ASA I \& II) neurosurgical patients. Three patients had a brain abscess and did not require emergency surgery. Thus, they were considered as elective patients and enrolled in our study. We acknowledge their specificity but confirm that similar results were observed after excluding them from the analysis. Although based on physiological rational, the $15 \%$ cutoff value used for SVV was arbitrary and other studies would be useful to investigate whether
Table 3 Postoperative outcome

\begin{tabular}{|c|c|c|c|}
\hline Parameters & $\begin{array}{l}\text { GDFR group } \\
(n=73)\end{array}$ & $\begin{array}{l}\text { Control group } \\
(n=72)\end{array}$ & $p$ value \\
\hline $\begin{array}{l}\text { ICU length of stay } \\
\text { (days) }\end{array}$ & $3(1-5)$ & $6(3-11)$ & 0.001 \\
\hline Mortality (n/\%) & $4 / 5.5$ & $9 / 12.5$ & 0.158 \\
\hline $\begin{array}{l}\text { Hospital length of stay } \\
\text { (days) }\end{array}$ & $15(7-23)$ & $17(9-27)$ & 0.069 \\
\hline \multicolumn{4}{|l|}{ Complications (day 30) } \\
\hline Total (n) & 46 & 99 & 0.043 \\
\hline $\begin{array}{l}\text { Patients with one or } \\
\text { more complications } \\
(\mathrm{n} / \%)\end{array}$ & 14/19.2 & $25 / 34.7$ & 0.034 \\
\hline Vomiting (n/\%) & $2 / 2.7$ & $2 / 2.8$ & 0.989 \\
\hline Coma (n/\%) & $3 / 4.1$ & $2 / 2.8$ & 0.660 \\
\hline Seizure (n/\%) & $1 / 1.4$ & $3 / 4.2$ & 0.304 \\
\hline $\begin{array}{l}\text { Encephaledema (CT/ } \\
\text { MRI) (n/\%) }\end{array}$ & $9 / 12.3$ & $16 / 22.2$ & 0.115 \\
\hline Pneumonia (n/\%) & $9 / 12.3$ & $20 / 27.8$ & 0.020 \\
\hline Sepsis (n/\%) & $0 / 0$ & $2 / 2.8$ & 0.152 \\
\hline $\begin{array}{l}\text { Ventilator support } \\
(\mathrm{n} / \%)\end{array}$ & $6 / 8.2$ & $12 / 16.7$ & 0.123 \\
\hline $\begin{array}{l}\text { New onset of ventila- } \\
\text { tor support }(n / \%)\end{array}$ & $3 / 4.1$ & $8 / 11.1$ & 0.111 \\
\hline $\begin{array}{l}\text { AKI (without dialysis) } \\
(\mathrm{n} / \%)\end{array}$ & $3 / 4.1$ & $5 / 6.9$ & 0.455 \\
\hline $\begin{array}{l}\text { Renal failure with } \\
\text { dialysis }(n / \%)\end{array}$ & $0 / 0$ & $1 / 1.4$ & 0.312 \\
\hline $\begin{array}{l}\text { Stroke (including TIA) } \\
(\mathrm{n} / \%)\end{array}$ & $1 / 1.4$ & $0 / 0$ & 0.319 \\
\hline $\begin{array}{l}\text { Deep vein thrombosis } \\
(\mathrm{n} / \%)\end{array}$ & $0 / 0$ & $4 / 5.6$ & 0.041 \\
\hline $\begin{array}{l}\text { Graft thrombosis } \\
(\mathrm{n} / \%)\end{array}$ & $0 / 0$ & $1 / 1.4$ & 0.312 \\
\hline $\begin{array}{l}\text { Wound infection/ } \\
\text { dehiscence (n/\%) }\end{array}$ & $0 / 0$ & $0 / 0$ & 1 \\
\hline Skin lesions (n/\%) & $8 / 11.0$ & $16 / 22.2$ & 0.068 \\
\hline $\begin{array}{l}\text { Arrhythmias (non-life } \\
\text { threatening) (n/\%) }\end{array}$ & $1 / 1.4$ & $2 / 2.8$ & 0.552 \\
\hline $\begin{array}{l}\text { Arrhythmias (life } \\
\text { threatening) (n/\%) }\end{array}$ & $0 / 0$ & $1 / 1.4$ & 0.312 \\
\hline $\begin{array}{l}\text { Heart failure/pulmo- } \\
\text { nary edema (n/\%) }\end{array}$ & $0 / 0$ & $4 / 5.6$ & 0.041 \\
\hline $\begin{array}{l}\text { Acute myocardial } \\
\text { infarction (n/\%) }\end{array}$ & $0 / 0$ & $0 / 0$ & 1 \\
\hline $\begin{array}{l}\text { Pulmonary embolism } \\
(\mathrm{n} / \%)\end{array}$ & $0 / 0$ & $0 / 0$ & 1 \\
\hline \multicolumn{4}{|l|}{ Costs } \\
\hline Hospital costs (\$) & $9218 \pm 2890$ & $10,249 \pm 3175$ & 0.482 \\
\hline ICU costs $(\$)$ & $1776 \pm 459$ & $3080 \pm 700$ & 0.037 \\
\hline
\end{tabular}

Values are presented as mean \pm standard deviation

ICU intensive care unit, AKI acute kidney injury

better results could be observed when using lower (e.g., $13 \%$ ) or higher (e.g., 18\%) cutoff values. Also, we cannot draw any conclusion regarding the superiority of 
Table 4 Patient characteristics during surgery

\begin{tabular}{|c|c|c|c|c|c|c|}
\hline Variable & Beginning of surgery & $1 \mathrm{~h}$ & $2 \mathrm{~h}$ & $3 \mathrm{~h}$ & $4 \mathrm{~h}$ & End of surgery \\
\hline \multicolumn{7}{|l|}{ Number } \\
\hline GDFR group & $73(100 \%)$ & $73(100 \%)$ & $73(100 \%)$ & $36(49 \%)$ & $25(34 \%)$ & $73(100 \%)$ \\
\hline Control group & $72(100 \%)$ & $72(100 \%)$ & $72(100 \%)$ & $37(51 \%)$ & $24(33 \%)$ & $72(100 \%)$ \\
\hline$p$ value & 1.00 & 1.00 & 1.00 & 0.80 & 0.92 & 1.00 \\
\hline \multicolumn{7}{|l|}{ MAP $(\mathrm{mmHg})$} \\
\hline GDFR group & $83 \pm 14$ & $75 \pm 9$ & $77 \pm 10$ & $77 \pm 11$ & $73 \pm 9$ & $82 \pm 11$ \\
\hline Control group & $80 \pm 15$ & $78 \pm 11$ & $80 \pm 14$ & $76 \pm 11$ & $82 \pm 11$ & $78 \pm 11$ \\
\hline$p$ value & 0.17 & 0.09 & 0.16 & 0.93 & 0.12 & 0.07 \\
\hline \multicolumn{7}{|l|}{$\mathrm{P}_{\mathrm{ET}} \mathrm{CO}_{2}(\mathrm{mmHg})$} \\
\hline GDFR group & $29 \pm 3$ & $29 \pm 4$ & $29 \pm 3$ & $29 \pm 3$ & $29 \pm 3$ & $31 \pm 4$ \\
\hline Control group & $30 \pm 3$ & $29 \pm 3$ & $29 \pm 3$ & $30 \pm 3$ & $32 \pm 4$ & $28 \pm 3$ \\
\hline$p$ value & 0.20 & 0.68 & 0.69 & 0.44 & 0.06 & 0.79 \\
\hline \multicolumn{7}{|l|}{ Sodium (mmol/l) } \\
\hline GDFR group & $137.8 \pm 4.8$ & $134.5 \pm 5.7$ & $135.9 \pm 4.7$ & $136.8 \pm 5.5$ & $136.2 \pm 3.3$ & $137.3 \pm 4.5$ \\
\hline Control group & $136.0 \pm 5.5$ & $134.3 \pm 5.8$ & $136.1 \pm 5.2$ & $137.4 \pm 5.3$ & $139.0 \pm 6.7$ & $137.5 \pm 5.1$ \\
\hline$p$ value & 0.03 & 0.81 & 0.86 & 0.64 & 0.07 & 0.84 \\
\hline \multicolumn{7}{|l|}{ Diuresis (ml/kg/h) } \\
\hline GDFR group & 0 & $5.58 \pm 1.74$ & $5.19 \pm 1.37$ & $4.97 \pm 1.85$ & $4.41 \pm 1.73$ & $4.12 \pm 1.39$ \\
\hline Control group & 0 & $5.76 \pm 1.50$ & $5.52 \pm 1.77$ & $5.03 \pm 1.63$ & $5.01 \pm 1.45$ & $4.12 \pm 1.39$ \\
\hline$p$ value & 1 & 0.52 & 0.18 & 0.92 & 0.26 & 0.80 \\
\hline
\end{tabular}

Values are presented as mean \pm standard deviation

$M A P$ mean arterial pressure, $P_{E T} \mathrm{CO}_{2}$ peak end-tidal $\mathrm{CO}_{2}$

our original GDFR strategy over a more classical goaldirected fluid strategy (e.g., stroke volume optimization) or over fluid restriction alone. The reliability of the FloTrac/Vigileo system to measure cardiac output has been questioned when compared to clinical reference techniques such as pulmonary thermodilution and echocardiography [19]. Of note, most limitations have been described in patients with septic shock receiving vasopressors, or during liver transplantation [20]. Recent meta-analysis of validation studies suggests that both accuracy and precision are comparable to those observed with other continuous cardiac output monitoring techniques currently available on the market [21]. And many studies have demonstrated that FloTrac-derived SVV is an accurate predictor of fluid responsiveness; pending limitations are respected [20].

\section{Conclusion}

In high-risk patients undergoing brain surgery, our intraoperative GDFR strategy was associated with a significant decrease in ICU length of stay, costs, and postoperative complications. Larger studies are needed to confirm our findings and assess the impact on hospital length of stay and hospital finances.

\begin{abstract}
Abbreviations
GDFR: goal-directed fluid restriction; ICU: intensive care unit; ASA: American Society of Anesthesiologists; Cl: cardiac index; SWV: stroke volume variation; HR: heart rate; MAP: mean arterial pressure; N/A: not applicable; POSSUM: physiological and operative severity score for the enumeration of mortality and morbidity.
\end{abstract}

\section{Authors' contributions}

GC, JL, and BL participated in study design and manuscript preparation. JL, JX, and GC participated in patient selection, intraoperative monitoring and management, data collection, analysis, and manuscript preparation. LL contributed to data collection. All authors read and approved the final manuscript.

\section{Acknowledgements}

We thank Dr Frederic Michard, Lausanne, Switzerland, for helping us to design the study and to review the manuscript.

\section{Competing interests}

The authors declare that they have no competing interests.

\section{Availability of data and materials}

Goal-directed fluid restriction in Neurosurgical Patients: A Prospective Randomized Controlled Trial, Poster Discussions Session PD04-2. Clinical Circulation: Hemostasis Coagulation, Monday, October 26, 2015, 3:30 pm-5:00 pm, Upper $11 \mathrm{~A}$.

\section{Funding}

This study was supported by the Science and Technology Department of Sichuan Province support program (No. 2013SZ0030).

Received: 25 August 2016 Accepted: 23 January 2017

Published online: 16 February 2017 


\section{References}

1. Bellamy MC. Wet, dry or something else? Br J Anaesth. 2006;97:808-16.

2. Lilot M, Ehrenfeld JM, Lee C, Harrington B, Cannesson M, Rinehart J. Variability in practice and factors predictive of total crystalloid administration during abdominal surgery: retrospective two-centre analysis. $\mathrm{Br} \mathrm{J}$ Anaesth. 2015;114:767-76.

3. Hamilton MA, Cecconi M, Rhodes A. A systematic review and metaanalysis on the use of preemptive hemodynamic intervention to improve postoperative outcomes in moderate and high-risk surgical patients. Anesth Analg. 2011;112:1392-402.

4. Grocott MP, Dushianthan A, Hamilton MA, Mythen MG, Harrison D, Rowan K. Perioperative increase in global blood flow to explicit defined goals and outcomes after surgery: a Cochrane Systematic Review. Br J Anaesth. 2013;111:535-48

5. Pearse RM, Harrison DA, MacDonald N, Gillies MA, Blunt M, Ackland G, et al. Effect of a perioperative, cardiac output-guided hemodynamic therapy algorithm on outcomes following major gastrointestinal surgery: a randomized clinical trial and systematic review. JAMA. 2014;311:2181-90.

6. Benes J, Giglio M, Brienza N, Michard F. The effects of goal-directed fluid therapy based on dynamic parameters on post-surgical outcome: a meta-analysis of randomized controlled trials. Crit Care. 2014;18:584.

7. Tummala RP, Sheth RN, Heros RC. Hemodilution and fluid management in neurosurgery. Clin Neurosurg. 2006;53:238-51.

8. Tommasino C. Fluids and the neurosurgical patient. Anesthesiol Clin North Am. 2002;20:329-46.

9. Michard F, Chemla D, Teboul JL. Applicability of pulse pressure variation: how many shades of grey? Crit Care. 2015;19:144.

10. Michard F, Biais M. Rational fluid management: dissecting facts from fiction. Br J Anaesth. 2012;108:369-71.

11. Holte K, Sharrock NE, Kehlet H. Pathophysiology and clinical implications of perioperative fluid excess. Br J Anaesth. 2002;89:622-32.
12. Thacker JK, Mountford WK, Ernst FR, Krukas MR, Mythen MM. Perioperative fluid utilization variability and association with outcomes: considerations for enhanced recovery efforts in sample US surgical populations. Ann Surg. 2016;263:502-10.

13. Yang $X$, Du B. Does pulse pressure variation predicts fluid responsiveness in critically ill patients: a critical review and meta-analysis. Crit Care. 2014;18:650.

14. Dunki-Jacobs EM, Philips P, Scoggins CR, McMasters KM, Martin RC. Stroke volume variation in hepatic resection: a replacement for standard central venous pressure monitoring. Ann Surg Oncol. 2014;21:473-8.

15. Sadique Z, Harrison DA, Grieve R, Rowan KM, Pearse RM, OPTIMISE study group. Cost-effectiveness of a cardiac output-guided haemodynamic therapy algorithm in high-risk patients undergoing major gastrointestinal surgery. Perioper Med (Lond). 2015;4:13.

16. Hand WR, Stoll WD, McEvoy MD, McSwain JR, Sealy CD, Skoner JM, et al. Intraoperative goal-directed hemodynamic management in free tissue transfer for head and neck cancer. Head Neck. 2016;38:1974-80.

17. Manecke GR, Asemota A, Michard F. Tackling the economic burden of post-surgical complications: would perioperative goal directed fluid therapy help? Crit Care. 2014;18:566

18. Ebm C, Cecconi M, Sutton L, Rhodes A. A cost-effectiveness analysis of postoperative goal-directed therapy for high-risk surgical patients. Crit Care Med. 2014;42:1194-203.

19. Camporota $L$, Beale R. Pitfalls in haemodynamic monitoring based on the arterial pressure waveform. Crit Care. 2010;14:124.

20. Slagt C, Malagon I, Groeneveld J. Systematic review of uncalibrated arterial pressure waveform analysis to determine cardiac output and stroke volume variation. Br J Anaesth. 2014;112:626-37.

21. Peyton PJ, Chong SW. Minimally invasive measurement of cardiac output during surgery and critical care: a meta-analysis of accuracy and precision. Anesthesiology. 2010;113:1220-35.

\section{Submit your manuscript to a SpringerOpen ${ }^{\odot}$ journal and benefit from:}

- Convenient online submission

- Rigorous peer review

- Immediate publication on acceptance

- Open access: articles freely available online

- High visibility within the field

- Retaining the copyright to your article

Submit your next manuscript at springeropen.com 